\title{
ENSINO E APRENDIZADO DO PORTUGUÊS PARA FALANTES DE ESPANHOL: UMA QUESTÃO DE FOGO E PAIXÃO
}

Elisabeth Salum ${ }^{*}$

\section{Fogo e paixão: o medo}

Não se pode negar a pequena quantidade e variedade de material didático de português como língua estrangeira publicado no Brasil. Os mais recentes saíram, há tempo, dos superlotados fornos editoriais e, por isso, não se pode dizer que há novidades quentes e apetitosas na mesa do professor. Nem mesmo que há alimento embalado para o sedento - embora a metáfora pedisse faminto - segmento de mercado gerado pelo Mercosul.

Até bem pouco tempo, nós aqui, falantes do português do Brasil, lidávamos com eles logo aí, falantes do espanhol da Argentina, da Bolívia, da Colômbia, do Paraguai, do Peru, do Uruguai e da Venezuela como se o Brasil e os países de fronteira fossem um grande palco para atores despreparados e pouco talentosos.

A nossa companhia parecia não ter o menor constrangimento em adulterar o texto original, dramatizando um português infantilmente decorado e primariamente maquiado com sons de um espanhol mal conhecido e nada estudado. Não era muito diferente o que ocorria com a maioria deles, mas havia uma ou outra trupe que se recusava a fazer essa triste figura, e contracenava em espanhol. Sem contato fronteiriço, os chilenos e equatorianos tinham menos chance de subir a esse palco e arriscar uma fala, que no dia seguinte podia virar piada.

\footnotetext{
- Professora de Cursos Extracurriculares - USP.
} 
Lá distantes, diante de um brasileiro na rua, é possível que os costa-riquenhos, cubanos, dominicanos, hondurenhos, guatemaltecos, mexicanos, nicaraguenses, salvadorenhos, panamenhos e porto-riquenhos tenham muitas vezes desistido do espanhol e tentado comunicar-se conosco em inglês.

Não é pra menos. A não ser nas escolas de orientação espanhola, francesa e italiana, da década de setenta até o início da década de noventa quem participava da educação média (ensino fundamental e médio) passou a entender inglês como sinônimo de língua estrangeira.

O mesmo inglês que na nossa década passou a ser secundado pelo espanhol, mas que ainda toma conta dos livros didáticos. Não só porque é a língua estrangeira sobre a qual mais se publicam livros didáticos e paradidáticos, no Brasil ${ }^{1}$, mas sobretudo porque é o ensino de inglês como língua estrangeira que está por trás da metodologia adotada pelos poucos autores e raríssimos editores de didáticos de português como língua estrangeira no Brasil².

No Bom dia e Boa noite de cada diálogo, ressoam os bem comportados Good morning e Good evening, mas não se ouvem os nossos ecos plurais do Buenos días e Buenas noches. Ecos que estão, p.ex., no 'as tarde! caipira de São Paulo e Minas, aos quais, Fernanda Torres, apesar do erre velarmente carioca, faz soar no longa-metragem A marvada carne ${ }^{3}$.

Foi numa liquidação de videolocadora que, por acaso, consegui o meu exemplar do filme que trata de hábitos e crendices brasileiras com humor e modernidade. Acaso é pouco: o que houve foi mesmo um golpe de sorte, porque no mesmo pacote desprezado pelo bem sucedido locador de filmes americanos veio também um filme chamado Fogo e paixão, que abriu a porta de um forno - que não é editorial, que não é de escala industrial, mas que oferece à gente que se interessa pelos estudos de língua uma iguaria quentíssima e deliciosa.

Vejam-se os catálogos de didáticos e paradidáticos de inglês e espanhol de cinco das maiores editoras brasileiras de didáticos e paradidáticos - Ática, Scipione, Moderna, FTD e Saraiva e o catálogo da Melhoramentos, que inclui gramáticas de espanhol e inglês, ambas bilíngües, com explicação em português, além dos dicionários em ambas as línguas.

2 Entre as pouquíssimas editoras brasileiras que se aventuram a publicar esse tipo de material (Pontes, Ibrasa, Pioneira), a EPU tem o maior número de títulos: três didáticos e dois paradidáticos.

3 A marvada carne. Tatu Filmes, 1985. Produção Cláudio Kahns. 
É do aproveitamento do trecho inicial desse filme - Fogo e paixão ${ }^{4}-$ como material de referência para a elaboração de material didático de português para falantes de espanhol que quero tratar aqui.

\title{
Fogo e paixão: a realidade
}

Na contracapa da caixa, o texto anuncia:

\begin{abstract}
"Este é o primeiro longa-metragem da dupla Isay Weinfeld e Marcio Kogan [...]. Fogo e Paixão foi a grande atração da XII Mostra Internacional de Cinema de São Paulo em 1988. Não por ser o único brasileiro, mas por ser um verdadeiro tributo à inteligência.

Comédia de costumes de altíssimo nível, marcada por piadas rápidas, surpreendentes e sequiências de grande impacto e beleza visual. Durante uma excursão de ônibus pelos pontos turísticos de uma São Paulo quase irreconhecível, você vai assistir a um verdadeiro desfile de tipos e personalidades estranhas, que contam com a brilhante participação de artistas da vanguarda teatral em São Paulo, como Carlos Moreno, Mira Haar e Cristina Mutarelli, além de gente famosa como Fernanda Montenegro, Rita Lee, Monique Evans, Paulo Autran, Tônia Carrero, Giulia Gam, Fernanda Torres, Regina Casé, Zezé Macedo, Roberto de Carvalho, Sérgio Mamberti e Nair Bello, entre outros. Humor sutil, refinado, não para gargalhar. Mas para rir e se sentir ainda mais inteligente."
\end{abstract}

Esse discurso publicitário da inteligência não é certamente o melhor que se poderia fazer a respeito do trecho inicial que escolhi para trabalhar com alunos falantes de espanhol do curso de Português como língua estrangeira do Centro de Línguas da FFLCH da USP no primeiro semestre de 99.

Longe do pedantismo e do pretenso elitismo intelectual, os diálogos de Flávio de Souza revelam sensibilidade (sem a qual se desfaz qualquer traço de inteligência) no trato de particularidades decorrentes das línguas e culturas em contato.

E não há coisa mais interessante para uma aula de português como língua estrangeira do que poder entrar, virtualmente, dentro um ônibus de turismo junto com

Fogo e paixão. WKW Filmes, 1988. Direção e roteiro de Isay Weinfeld e Marcio Kogan. Diálogos de Flávio de Souza. 
brasileiros de São Paulo e turistas dos Estados Unidos, da França, do Japão, de Portugal e da Rússia.

\section{Fogo e paixão: o confronto}

O trecho do filme utilizado como material de referência é justamente a sequiência da acomodação dos turistas no ônibus, liderados por uma guia provavelmente argentina e guiados por um motorista brasileiro.

Fazem parte do trecho escolhido os seguintes tipos:

- as amigas Vilma e Helena, clara caricatura de Telma e Louise, na busca de um parceiro afetivo;

- um solteirão aparentemente convicto por quem Vilma se interessa;

- um duque janota, de nome pomposo (Demétrio Bernardo Adolfo), por quem ambas se interessam;

- uma senhora que só diz $E$, a qualquer observação que lhe façam, acompanhada da filha e de meia dúzia de netas, estereotipadamente barulhentas e agitadas;

- um português que diz apenas uma frase - Não me toques nisto! - com o-e do pronome mudo e o $-s$ do verbo, na segunda pessoa do singular, devidamente chiado;

- um casal de americanos, que reproduzem exercícios de repetição e fixação de estruturas gramaticais, como se fossem a corporificação das vozes das fitas dos métodos de inglês;

- uma francesa, que não diz outra coisa senão Merde!;

- um japonês, que não abandona a filmadora e fala $H i$ ! e $O k$ ! pronunciado / oka/, e

- uma russa que se dirige aos outros na sua língua como se todos pudessem compreendê-la.

Não bastassem todas essas inferências culturais e lingüísticas, os diretores e roteiristas criaram a oportunidade de um grande diálogo no filme.

Um diálogo em que português e espanhol não se deixam mais dominar pelo portunhol ou pela resistência ao contato. As duas línguas afirmam-se como irmãs 
gêmeas bivitelinas, que se reconhecem na sua identidade mas se diferenciam na sua particularidade.

São filhas voluntariosas de uma mãe românica que confiou sua criação a uma mesma ama-de-leite: uma Ibéria cheia de fogo e paixão.

\section{Fogo e paixão: o encontro}

A consciência, de um lado, de que a língua de cada um dos dois interlocutores é a expressão de duas identidades distintas - o que não interfere na compreensão básica entre falantes do português e espanhol - e, de outro, de que existem fortes pontos de contato entre essas identidades - o que não determina que português e espanhol se fundam no portunhol - é o que se percebe nos diálogos entre a guia e o motorista:

"guia: Apaga eso [referindo-se ao rádio], che!

guia: Por ultima vez, apaga esa...

motorista: Ih, que é que é, tá nervosa, é?

guia: Viendrá por fin este tío?

motorista: É, se vier, a gente logo vai saber quem é.

guia: Escucha, a tí te parece que Sergio estava hablando en serio?

motorista: Acredita se quiser. Vai por mim. Os fiscais agora vêm disfarçados. Você não notou que não apareceu mais nenhum com aqueles caderninhos?

guia: Pos claro!

motorista: Entonces!

guia: Tiene que ser este tío el inspector. Mira la facha! Puede no estar com este maldito cuaderno, pero com esta cara de disgraciado...".

Em português e em espanhol, apagar é usado com o sentido de "desligar". No português do Rio Grande do Sul, usa-se o mesmo che, que em outras partes do Brasil se substitui perfeitamente por cara. Tío pode ser traduzido por cara, mas também por tio, "homem mais velho", cuja esperada implicância corresponde bem à carga depreciativa que a guia confere ao fiscal da companhia de viagens. Tener que é "dever" tanto quanto ter que.

Mas nem tudo são semelhanças. Se este existe em português e em espanhol, eso e esa são pronomes que, no contato das duas línguas, se sobrepõem ao isso e essa. 
Por ultima vez ganha artigo, contraído com a preposição, e acento na proparoxítona: pela última vez. Viendrá tem tradução mais natural na perífrase verbal vai vir - coloquialmente realizado como vai vim -, e não no tempo verbal virá. Por fin isoladamente seria afinal, mas melhor tradução para a frase seria "Será que esse cara vem mesmo?". En serio é a sério ou, quando muito, sério. Os ditongos crescentes de puede e cuaderno se desfazem nas vogais abertas de pode e caderno. Antes de ser porém, pero é "mas".

E nem tudo são intolerâncias. O motorista concede e diz ¡Entonces! É certo que com uma entonação toda característica do nosso Então!, sem ponto de exclamação invertido, aliás! E a guia tampouco (em português, mais natural seria também não) fica atrás: diz escucha, tão naturalmente como se estivesse dizendo mira.

\title{
Fogo e paixão: o ciúme
}

\author{
“ \\ guia: Apaga eso, che! \\ motorista: Mas não sou eu [a música agora é in off, não sendo, portan- \\ to, da responsabilidade da atuação dos personagem]".
}

Tivéssemos sido nós largados pela mãe românica numa insignificante península, falaríamos hoje talvez com mais simplicidade. Mas não somos órfãos nem rejeitamos a contribuição das outras irmãs.

Esa seguido de reticências, no contexto em que foi usado, só pode querer introduzir merda, em português, e mierda, em espanhol. Por mais que queiram, os franceses não podem concorrer conosco: exclamam Merde! muito mais do que dizem cette merde!.

Se para a guia de turismo facha é espanhol, para o motorista, ainda deve ser faccia, com sentido mais de "cara" que de "jeito".

E, por mais saludos que eles nos dêem, aqui vai o nosso abraço, cumprimentos, saudações. Tchau - muito diferente do cumprimento italiano, escrito ciao - é nosso adiós. 


\section{Fogo e paixão: a reconciliação}

Filhos de uma mesma mãe, o catalão, o espanhol, o francês, o galego, o italiano, o português, o rético, o romeno e o sardo são, como todas as línguas, "expressão de uma identidade coletiva e de uma forma distinta de perceber a realidade"s.

Nós, falantes do português e do espanhol das Américas, somos herdeiros de uma cultura românica, que, por mais desconhecida que seja, deve ser preservada, contrastada e compreendida nas suas particularidades.

Para isso, é preciso estudar e conhecer a estrutura dessas nossas línguas, com o mesmo amor como se estuda e se conhece a própria. E nesta década estamos tendo a oportunidade de fazer isso com o espanhol.

Mais do que lamentar a falta de material didático, precisamos lutar para que se preserve e se valorize a produção cultural brasileira. São as nossas músicas gravadas, os nossos filmes lançados em VHS, as nossas artes plásticas fotografadas, os nossos textos impressos que constituem o material de referência usado por nós, que temos o privilégio de trabalhar dentro do Brasil.

E é essa cultura documentada que os livros didáticos devem levar para fora do país, mostrando o que é que as variantes do português falado e escrito do Brasil têm como língua de cultura e disponibilizando aos professores que não estão aqui o trabalho com uma língua às vezes agressiva, às vezes gentil, mas sobretudo cheia de vida.

Só assim será possível sentir, de fato, como arde o nosso fogo, a nossa paixão.

5 Declaração Universal de Direitos Lingüísticos, Art. 7.1 